\title{
Isolation, Characterization and Bioremediation Potentials of Spent Engine Oil Degrading Fungi from Contaminated Soil
}

\author{
D.A. Duniya ${ }^{1}$, D.B. Maikaje², Y.A. Umar³, Daniel Abba ${ }^{4, *}$, P. Omokunmi ${ }^{3}$ \\ ${ }^{1}$ Department of Environmental Science, College of Environmental Studies, Kaduna Polytechnic, Kaduna, Nigeria. \\ ${ }^{2}$ Department of Microbiology, Kaduna State University, Kaduna, Nigeria. \\ ${ }^{3}$ Department of Biological Sciences, Nigerian Defence Academy Kaduna, Nigeria. \\ ${ }^{4}$ Department of Biochemistry, Ahmadu Bello University, Zaria, Nigeria.
}

\section{ARTICLE DETAILS}

Article history:

Received 23 March 2018

Accepted 13 April 2018

Available online 26 April 2018

\section{Keywords:}

Fungi

Bioremediation

Spent Engine Oil

\begin{abstract}
A B S T R A C T
The ability of Fungal Isolates to utilize spent engine oil in contaminated soils from some ten selected major mechanic workshops in Kaduna metropolis as sole source of carbon and energy was studied. Microbes were isolated from ten (10) used engine oil contaminated automobile workshops within Kaduna metropolis and assessed for their bioremediation potential. The identities of the isolated microbes were determined using biochemical and molecular characterization techniques. These organisms were further studied to determine their biodegrading activities on hydrocarbons (used engine oil) using mineral salt medium broth. Fungal species isolated includes Aspergillus niger, Rhizopus $s p$., Pennicillium sp. and mixed fungal consortium in the following percentages $23.07 \%, 15.38 \%, 7.69 \%$ and $76.36 \%$ respectively. The growth rate pattern in decreasing order is mixed fungi isolates> Aspergillus niger > Rhizopus sp. > Penicillum sp. Therefore, these microbial isolates can be applied for the restoration of petroleum polluted environment using bioremediation technology and should be consider as trial for further pilot studies.
\end{abstract}

\section{Introduction}

Petroleum pollution is a global problem, with the commonest occurrence in the oil producing and industrial regions [1]. Petroleum pollution of environments is dangerous for plants, animals and people [2, 3]. Nigeria, as an oil producing country is plaque by petroleum products pollution in both the producing and other environments with increasing rates in recent years [4]. Used engine oil can be considered as one of the sources responsible for polluting the soil with hydrocarbons. Used engine oil consists of petroleum ether or benzine, gasoline, naptha, minerals spirits, kerosene, fuel oil, lubricating oil, paraffin wax, asphalt or tar. Used oil typically has much higher concentration of PAHs (polycyclic aromatic hydrocarbons) than new motor oil. .One of the most significant environmental impact emanating from mechanic workshop seepage of used engine oil includes loss of soil fertility, water holding capacity, permeability, binding capacity, surface and underground water quality, plants and soil microbes [5].

There are several hydrocarbon soil cleaning methods including burning, washing, chemical application and bioremediation [6]. Bioremediation is the use of plants and microorganisms to remove or detoxify environmental contaminants. Bioremediation has been intensively studied over the past two decades, as an alternative lower cost sustainable with natural environment cleaning technology for environmental restoration in the place of the more expensive engineeringbased remediation technologies $[1,7,8]$.

Bioremediation of petroleum contaminated soils is mainly based on biodegradation by the fungal and bacteria strains that are present in the associated microbes or in the soils of petroleum polluted sites [9]. Some prior researchers reported that some fungal species are resistant to petroleum-pollution and they are capable of removing soil pollution. This research focuses on isolation of fungal strains from engine oilcontaminated soils of mechanic workshops in Kaduna metropolis, evaluation of their ability in removing of engine oil pollution in experimental conditions and determination of their potential genetic activity during hydrocarbon removal.

\section{Experimental Methods}

\subsection{Isolation of Fungi}

The fungi were isolated by inoculating each soil sample on autoclaved Bushnell Haas Agar medium as a selective medium enriched with (1\% used engine oil) as a sole carbon enrichment source. The medium was also inoculated with 100 microgram of streptomycin in order to suppress bacterial contamination. The isolates were further subcultured into Sabouraud agar medium to obtain pure cultures of each species for molecular analysis as described [10].

\subsection{Morphological Identification of Fungal Isolates}

Each pure fungal isolate was identified grossly by visual observation according to the general principles of fungal classification based on the nature of mycelium and growth patterns. In addition, the fruit body of each isolated fungus that contained the sporangium and spores was harvested and stained using acid Fuschin and examined under light microscope for morphological identification.

\subsection{Isolation of Genomic DNA from Fungi}

The genomic DNA of each fungus with observed remediation capabilities was isolated. $1 \mathrm{ml}$ of each fungal culture was pellated by centrifuging at $12,000 \mathrm{rpm}$ for $2 \mathrm{~min}$, the pellet was treated with lysis solution and proteinase $\mathrm{k}$ and incubated at $60{ }^{\circ} \mathrm{C}$ for $30 \mathrm{~min}$. Deoxyribose nucleic acid (DNA) was extracted from each fungus precipitated with isopropanol by centrifuging at $10,000 \mathrm{rpm}$ for $10 \mathrm{~min}$, washed with $1 \mathrm{~mL}$ of a $70 \%(\mathrm{v} / \mathrm{v})$ ethanol solution and dissolved in $0.1 \mathrm{ml}$ of a TE buffer. The purity and quantity of DNA of each sample was examined using UV absorption spectrum and agarose gel (1\% electrophoresis) $[10,11]$.

\subsection{Polymerase Chain Reaction Amplification of $16 \mathrm{~s}$ rRNA}

The PCR reaction mixture containing 10XPCR buffer, $25 \mathrm{mM}$, magnesium chloride, $2.5 \mathrm{mM}$ dNTP's , $10 \mathrm{pm} / \mu \mathrm{L}$ primer concentrations, and template DNA were used for the amplification of the $16 \mathrm{~s}$ rRNA for each fungal isolate. PCR conditions were optimized using lab net thermal cycler. The PCR program began with an initial 5-min denaturation step at $94^{\circ} \mathrm{C}$; 35 cycles of $94^{\circ} \mathrm{C}$ for $45 \mathrm{sec}, 55^{\circ} \mathrm{C}$ for $1 \mathrm{~min}, 72^{\circ} \mathrm{C}$ for $1 \mathrm{~min}$; and a final 
10 min extension step at $72{ }^{\circ} \mathrm{C}$. All reaction mixtures were preserved at 4 ${ }^{\circ} \mathrm{C}$ until it was time for analysis as previously reported [12]. The amplified 16s rRNA of each fungal isolate was further characterised using agarous gel electrophoresis.

\subsection{Sequence Determination of 16 s rRNA}

The amplified 16s rRNA of each fungal isolate was processed for sequencing and characterization. The sequence of the 16s rRNA was determined with a dye terminator sequencing kit (applied biosystems), and the product was analyzed with an ABI Prism DNA sequencer (ABI). The gene sequences of each isolate obtained in this study were compared with known 16s rRNA gene sequences in the GeneBank database [11].

\subsection{Amplification of Hydrocarbon Degrading Enzyme Catechol 2, 3} Dioxygenase Coding Gene

The microbes were molecularly screened for the presence of catechol 2, 3 dioxgyenase enzyme genes that are involved in hydrocarbon biodegradation. Subsequently, PCR analysis and amplification of these genes was carried out according to the prescribed method of Jyothi et al. [11].

\subsection{Determination of Petroleum Oil Biodegradability of Fungi Isolates}

Turbidometry was used to determine the fungal growth pattern of the fungal isolates, utilizing spent engine oil provided in the mineral salt medium as carbon source. The biodegrading activities of each fungal isolate were determined by using mineral salt broth to which was added $1 \%$ spent engine oil. The inoculated fungus in each tube containing the medium composition was incubated for 40 days at room temperature (28 ${ }^{\circ} \mathrm{C}$ to $30^{\circ} \mathrm{C}$ ). The test tubes were shaken constantly throughout the duration of the experiment to facilitate oil-cell phase contact. The ability to biodegrade the petroleum products (based on the growth rate of the organisms in the mineral salt medium was measured every 5 days using the turbidity of the mineral salt measured by the photoelectric colorimeter. The fungal growth rate of each fungus was measured by taking the Optical Density (O.D) readings at $595 \mathrm{~nm}$ from zero hours - 40 days at regular intervals of 5 days against mineral salt broth medium as blank as demonstrated by Jyothi et al. [11].

\section{Results and Discussion}

3.1 Isolated Fungi and Characteristics from Spent Engine Oil in Sampled Locations

Fungal loads $\left(\mathrm{x}^{1} 0^{6}\right)$ obtained from spent engine oil-polluted soil collected from contaminated soil in Kaduna metropolis are presented in Table 1. Soil samples collected from Trikania and Ori-Akpta had fungal counts of $\mathrm{CFU} / \mathrm{mL}, 11.13 \pm 0.52$ and $39.42 \pm 0.96 \mathrm{CFU} / \mathrm{mL}$, respectively while the fungal population of the uncontaminated soil samples was $10.04 \pm 0.72 \mathrm{CFU} / \mathrm{mL}$.

Table 1 Fungal isolates from ten sampled mechanic workshops in Kaduna metropolis

\begin{tabular}{ll}
\hline Location & Fungal Count $\left(\times 10^{6} \mathrm{CFU} / \mathrm{mL}\right)$ \\
\hline Artillery & $26.21 \pm 1.0$ \\
Barnawa Railway & $17.65 \pm 1.23$ \\
Kawo & $23.45 \pm 0.54$ \\
Kurmi Mashi & $25.17 \pm 0.64$ \\
Malali & $27.32 \pm 1.21$ \\
Ori-Akpata & $39.42 \pm 0.96$ \\
Panteka & $34.64 \pm 2.10$ \\
Sabo/Tasha & $25.16 \pm 0.74$ \\
Trikania & $11.13 \pm 0.52$ \\
Television Garage & $37.21 \pm 0.84$ \\
Control & $10.04 \pm 0.72$ \\
\hline
\end{tabular}

3.2 Characteristics of Fungi Isolated from Spent Engine Oil Contaminated

\section{Soil in Mechanic Workshops in Kaduna Metropolis}

Three (3) fungal genera were isolated in all the ten sampled spent oil polluted mechanic workshops (Table 2). The growth appearances of these fungal isolates observed on the Sabouraud dextrose agar were black, yellowish green to dark green, yellowish green or yellowish brown with Mycelia and Spores. Microscopic examinations of acid Fuschin stain of the fungal isolate revealed probable features of Aspergillus niger, Pennicilium $s p$. and Rhizopus sp. The identities of this fungal isolates where further tentatively and confirmed with the PCR test exhibiting the agarose gel band on base pair position of 730bp (Fig. 1).

https://doi.org/10.30799/jespr.125.18040105
Table 2 Characteristics of fungi isolated from spent engine oil contaminated soil in mechanic workshops in Kaduna metropolis

\begin{tabular}{lll}
\hline $\begin{array}{l}\text { Fungal isolate cultural } \\
\text { appearance (visual) }\end{array}$ & Microscopic features & Name of probable fungus \\
\hline Black mycelium & $\begin{array}{l}\text { Conidiophores were } \\
\text { upright, branched, simple } \\
\text { and terminating in a } \\
\text { globose swelling. Bore } \\
\text { phialides at the apex }\end{array}$ & \\
& Aspergillus niger \\
Yellowish green to dark & $\begin{array}{l}\text { Conidiophores arranged } \\
\text { green hyphae }\end{array}$ & Penicillium sp. \\
& $\begin{array}{l}\text { mycelium. They were } \\
\text { mostly ovoid or globose } \\
\text { near the apex }\end{array}$ & \\
Grey or yellowish brown & $\begin{array}{l}\text { Sporangiospores singly, } \\
\text { globose sporangia, }\end{array}$ & Rhizopus sp. \\
with spoorulation & mycelia fuse & \\
\hline
\end{tabular}

MI 12345678910

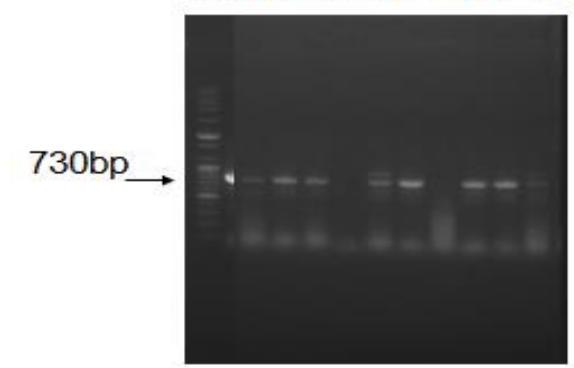

Fig. 1 PCR Agarose gel electrophoretic analysis of the amplified 16S rRNA for the fungal isolates from the ten study site in Kaduna metropolis (Lane 1 DNA marker(ladder), lane 2 Aspergillus niger, Lane 3 Rhizopus sp., Lane 5 Penicellium sp., Rhizopus sp., Lane 6 Aspergillus niger and Lane 7 Penicellium sp.)

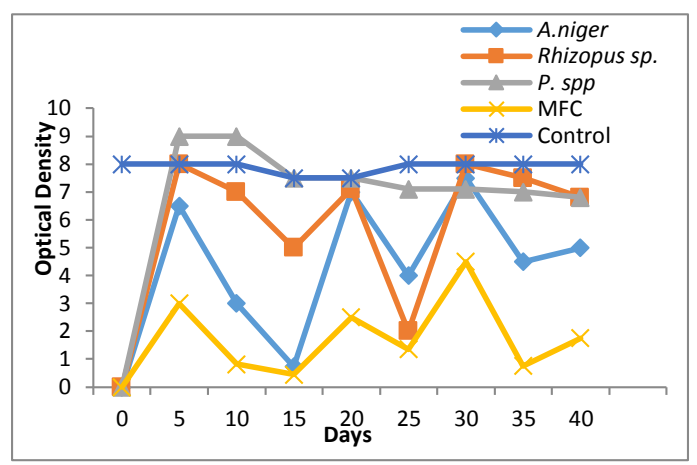

Fig. 2 the growth pattern of fungi in minimal salt medium broth supplemented with $1 \%(\mathrm{v} / \mathrm{v})$ spent engine oil

\subsection{The Growth Potential of Hydrocarbon Utilizing Fungi (Hydrocarbons by Turbidometry)}

In this study, three pure fungal isolates with different morphological characteristics were successfully isolated from the ten different types of soil samples contaminated with used engine oil. The fungal isolates showed difference in morphological appearance, pigmentation and sporulation in different media. Based on the macroscopic and microscopic morphological characteristics, the three fungal isolates belongs to the genus Rhizopus sp., Aspergillus sp., and Penicillium sp. respectively were recorded. Aspergillus niger had a maximum growth peak at optical density 7.5 on the $30^{\text {th }}$ day. Rhizopus sp. had maximum growth peak at optical density 8.0 on the $5^{\text {th }}$ and $30^{\text {th }}$ days respectively. Penicillium $s p$. had the lowest growth peak at optical density 9.0 on the $5^{\text {th }}$ and $10^{\text {th }}$ day while the mixed fungal consortium (MFC) had the highest growth peak at optical density 0.45 on $15^{\text {th }}$ day. On the $40^{\text {th }}$ day of incubation, Pennicilium $s p$. had the lowest growth peak at 7.5 followed by Rhizopus sp. at 6.8, Aspergillus niger at 5.20 and mixed fungal consortium (MFC) 1.75. Aspergillus niger had the best ability to degrade spent engine oil while Pennicilium $s p$ had the least ability, the mixed fungal consortium proved to be a better degrader when compared with the single fungal isolates. The analysis of variance result shows that there is a significant difference in the overall growth pattern of fungi in MSM broth supplemented with $1 \% \mathrm{v} / \mathrm{v}$ spent engine oil $(p>0.05)$. The overall result also indicates that the growth rate increased significantly from the zero hour to the $5^{\text {th }}$ day (Fig. 2) and appendix B. The below analysis shows that the MFC has significantly $(\mathrm{p}<0.05)$ lower optical density, implying that it has the highest growth. 
While the Rhizopus sp. has significantly $(\mathrm{p}<0.05)$ higher optical density than other species.

The results of this study indicate that many of the fungal species isolated from the engine oil contaminated mechanic workshops were Penicillium sp., Aspergillus sp. and Rhizopus sp. This result agrees with the findings of Okerentugba et al. which demonstrated that Penicillium sp., Aspergillus sp. and Rhizopus sp. were capable of biodegrading hydrocarbons [13]. These fungi had been isolated also from aquatic environments in the Niger Delta area of Nigeria. Battelle showed that fungi where better biodegraders of petroleum oil than bacteria [14]. Furthermore, Bartha and Athlas listed 14 genera of fungi which had been demonstrated to contain members which utilize petroleum hydrocarbons; all of these microorganisms had been isolated from hydrocarbon contaminated environment [15]. It is observed from this study that when the environment was contaminated with spent engine oil components the proportion of hydrocarbon-degrading microorganisms' increases rapidly. High numbers of certain hydrocarbon-degrading microorganisms from an environment implies that those organisms are the active biodegraders of these compounds in that environment [16]. The presence of oil-degrading organisms in the polluted soil suggests that the indigenous microbes were carrying out their metabolic activity. The activities of these microorganisms could be responsible for the bioremediation of the environment.

For the fungi isolate the highest was Aspergillus niger followed by Rhizopus sp. and the Penicillum sp. (Table 1). The result is similar with the report made by Ekaise and Nkwelle [17] whose research isolated Aspergillus $s p$. as the dominant species among their fungi isolates.

It was also observed in this study that fungi pattern of growth and development is much less predictable. Fungi were not fixed into a developmental pathway. This finding is in line with the report of Robson [18] who reported that the life cycle of a fungus is unpredictable and flexible. The growth phases demonstrated by the fungi identified in these studies shows that the pattern of growth displayed must have responded to the fixed nutrients of mineral salt medium supplemented with $1 \%$ spent engine oil. The stages of growth are typical of any organism growing in a fixed quantity of nutrient. Every single isolate of fungus grew rapidly in the beginning that is the exponential phase. This could be attributed to their previous association with oil contaminated environment. It is important to note that fungi isolate were initially isolated from variable environments with variation in deposition of organic nutrients and environmental factors, so their pattern of growth in the fixed nutrient under laboratory conditions may not be the same. The growth pattern of fungi in mineral salt medium solution in this study shows that the growth rate of each fungus had different maximum growth peaks. There was fluctuation in the growth of each fungus. The marked fluctuation in the growth rates was probably due to the differences in growth rates of each fungus with each fungi attaining a maximum growth peak and declining after some days, probably as a result of exhaustion of nutrients and release of toxic materials into the medium. The growth pattern of fungi in spent engine oil and minimal salt broth is represented in Fig. 2 . The growth rate pattern in decreasing order is mixed fungi isolates> Aspergillus niger $>$ Rhizopus sp. > Penicillum sp. Similar studies were reported by Adekunle and Adebambo where Rhizopus sp., Aspergillus niger and Taraomyces growth rate were recorded with Rhizopus sp. and Aspergillus niger having the best ability to degrade spent engine oil [19]. Similarly Olukunle identified Penicillum italicum, Penicillum oxalicum, Aspergillus niger, and Articylosporium inflata as good fungal spent engine oil degraders [20]. In this study, the mixed fungal consortium perform better than the single culture isolates of the fungi species which may be as a result of a synergistic interaction of the fungal isolates. Similar research was done by [13] which reported that a single microbe does not possess the enzymatic capability to degrade all or even most of the organic compounds in a polluted soil but mixed microbial communities possess powerful biodegradable potential because the genetic information of more than one organism is necessary to degrade the complex mixtures of organic compounds present in contaminated areas.

This result might also be due to the fact that the fungi isolated were able to use the hydrocarbons as substrates for growth by probably releasing extra cellular enzymes and acids which are capable of breaking down the recalcitrant hydrocarbon molecules, by dismantling the long chains of hydrogen and carbon, thereby, converting petroleum into simpler forms or products that can be absorbed for the growth and nutrition of the fungi. After being completely broken down, the reaction releases carbon (IV) oxide, water and energy used to create cellular biomass [19]. However, it must be noted that there were also nutrients present in the minimal salt broth though more of it could have been present in the oil which stimulated the growth of each fungus. From this work, it could be concluded that fungal strains isolated from contaminated soil are good spent engine oil degraders, as demonstrated in the growth rate and pattern of isolated bacteria and fungi on MSM broth inoculated with $1 \%$ engine oil.

\section{Conclusion}

From this work, it could be concluded that fungal strains isolated from contaminated soil are good spent engine oil degraders, as demonstrated in the growth rate and pattern of isolated bacteria and fungi on MSM broth inoculated with $1 \%$ engine oil.

\section{References}

[1] N. Merkel, R. Schultez-Kraft, C. Infante, Phytoremediation of petroleum contaminated soils in the tropics-preselection of plant species from eastern Venezuela, J. Appl. B. Food Qual. 78 (2004) 185-192.

[2] J. Santodonato, P. Howard, D. Basu, Health and ecological assessment of polynuclear aromatic hydrocarbons, J. Environ. Path. Toxicol. 5 (1981) 351364 .

[3] M.S. Prasad, K. Kumari, Toxicity of crude oil to the survival of the fresh water fish puntius sophore (HAM.), Acta Hydro. Ethydro. 15 (2006) 26-36.

[4] Petroleum Ministry Data Center, Petroleum accidents in Iran, Available at: www. khabaronline.ir (Accessed on: 24.03.2012)

[5] S.P. Moorthi, M. Deeccaran, T.P. Kalaichelvan, Bioremediation of automobile oil effluent by Pseudomonas sp., Adv. Biotech. 31 (2008) 34-36.

[6] M.M.G. Gallegos, S.A.G. Gomez, C.L.G. Gonzalez, G.M.A. Montes, T.L.Y. Yanez, L.J.A. Zermeno, R.M. Gutierrez, Diagnostic and resulting approaches to restore petroleum-contaminated soil in a Mexican tropical swamp, Water Sci. Technol. 42 (2000) 377-384.

[7] A. Chehregani, B. Malayeri, Removal of heavy metals by native accumulator plants, Int. J. Agri. Biol. Sci. 9 (2007) 462-465.

[8] A. Chehregani, M. Noori, H. Yazdi, Phytoremediation of heavy metal polluted soils: screening for new accumulator plants and evaluation of removal ability, Ecot. Environ. Safety 72 (2009) 1349-1353.

[9] C.M. Frick, R.E. Farrell, J.J. Germida, Assessment of phytoremediation as an Insitu technique for cleaning oil-contaminated sites, Calgary: Petrol. Technol., Alliance, Canada, 1999.

[10] R. Thenmozhi, K. Arumugam, A. Nagasathya, N. Thajuddin, A. Paneerselvam, Studies on mycoremediation of used engine oil contaminated soil samples, Adv. Appl. Sci. Res. 4(2) (2013) 110-118.

[11] K. Jyothi, K.B. Surendra, C.K. Nancy, A. Kashyap, Identification and isolation of hydrocarbon degrading bacteria by molecular characterization, Helix. 2 (2012) $105-111$.

[12] K. Kloos, J.C. Munch, M. Schloter, A new method for the detection of alkane monoxygenase homologous genes (alkb) in soil based on pcr- hybridization, J. Microbiol. Meth. 66 (2006) 486-496.

[13] P.O. Okerentugba, O.U. Ezeronye, Petroleum degrading potentials of single and mixed microbial cultures isolated from rivers and refinery effluent in Nigeria, Afr. J. Biotech. 2 (2003) 288-292

[14] C.D. Battelle, Mushrooms: Higher microfungi to clean up the environment, Battelle Environmental issues, New York, 2000.

[15] R. Bartha, R.M. Athlas, The microbiology of aquatic oil spills, Adv. Appl. Microb. 22 (1973) 225-266.

[16] D.Y. Kebria, A. Khodadadi, H. Ganjidoust, A. Badkoubi, M.A. Amoozegar, Isolation and characterization of a novel native Bacillus strain capable of degrading diesel fuel, Int. J. Environ. Sci. Technol. 6(3) (2009) 435-442.

[17] F.O. Ekaise, J. Nkwelle, Microbiological and physicochemical analyses of oil contaminated soil from major motor mechanic workshops in Benin City metropolis, Edo State, Nigeria, J. Appl. Sci. Environ. Manag. 15(4) (2011) 597600.

[18] G.D. Robson, P. van West, G.M. Gadd, Exploitation of fungi, Cambridge University Press, Cambridge, England, 2007.

[19] A.A. Adekunle, A.O. Adebambo, Petroleum hydrocarbon utilization by fungi isolated Detarium senegalense (J.F. Gmelin) seeds, J. Am. Sci. 3(1) (2007) 1-25.

[20] O.F. Olukunle, Characterization of indigenous microorganisms associated with crude oil-polluted soils and water using traditional techniques, Microbiol. Jour. 3 (2013) 1-11. 